\title{
NOD2 gene mutations in ulcerative colitis: useless or misunderstood?
}

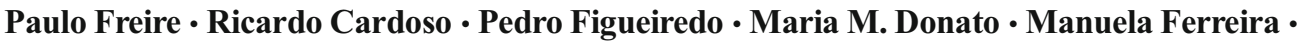 \\ Sofia Mendes • Ana Margarida Ferreira • Helena Vasconcelos • Francisco Portela • \\ Carlos Sofia
}

Accepted: 9 March 2014

(C) Springer-Verlag Berlin Heidelberg 2014

\begin{abstract}
Purpose NOD2 mutations have been linked to an increased risk of Crohn's disease and to some of its phenotypes. The association between NOD2 mutations and susceptibility to ulcerative colitis (UC) remains somewhat controversial and potential correlations between these mutations and UC phenotype have not been studied.

Aim To assess whether NOD2 mutations are a risk factor for $\mathrm{UC}$ in Portugal and if there are any genotype-phenotype correlations in these patients.

Methods The three main NOD2 mutations were searched in 200 patients with UC and in 202 healthy controls.

Results NOD2 mutations were present in 28 patients with UC $(14.0 \%)$ and in 27 controls $(13.4 \%)(p=0.853)$. Mutation carriers were more likely to receive steroids during the first
\end{abstract}

\author{
Paulo Freire and Ricardo Cardoso contributed equally to the article. \\ P. Freire $(\bowtie) \cdot$ R. Cardoso $\cdot$ P. Figueiredo $\cdot$ M. Ferreira \\ S. Mendes $\cdot$ A. M. Ferreira $\cdot$ F. Portela $\cdot$ C. Sofia \\ Department of Gastroenterology, Centro Hospitalar e Universitário \\ de Coimbra, Avenida Bissaya Barreto, 3000 Coimbra, Portugal \\ e-mail: pauloavfreire@gmail.com \\ R. Cardoso \\ e-mail: racardoso@gmail.com \\ P. Figueiredo \\ e-mail:pnf11@sapo.pt \\ M. Ferreira \\ e-mail: malvesferreira@netcabo.pt \\ S. Mendes \\ e-mail: msofiamendes@iol.pt \\ A. M. Ferreira \\ e-mail: magaidaferreira@gmail.com \\ F. Portela \\ e-mail: fasportela@gmail.com \\ C. Sofia \\ e-mail: carlossofia@huc.min-saude.pt
}

year of disease than non-carriers (54.2\% vs. $29.6 \%, p=$ 0.018 ) and among these patients the need for intravenous administration was more frequent in those with the R702W polymorphism $(90.0 \%$ vs. $45.5 \%, p=0.014)$. In patients with severe colitis admitted for intravenous steroids, a greater proportion of mutation carriers was considered intravenous-steroid refractory and required salvage therapy ( $90.0 \%$ vs. $38.1 \%, p=0.004)$. Patients with NOD2 mutation were submitted to colectomy more frequently than non-carriers $(17.9 \%$ vs. $4.1 \%$. $p=0.015)$. No correlation with the need for immunosuppressants/immunomodulators was found.

Conclusions In the Portuguese population, NOD2 mutations do not increase the risk of UC but are associated with a more aggressive course including greater need of steroids in the first

P. Figueiredo $\cdot$ M. M. Donato $\cdot$ C. Sofia

Center of Gastroenterology, Faculty of Medicine,

University of Coimbra,

Avenida Bissaya Barreto, 3000 Coimbra, Portugal

M. M. Donato

e-mail: mariamanueldonato@gmail.com

H. Vasconcelos

Department of Gastroenterology, Centro Hospitalar Leiria-Pombal, Rua das Olhalvas, 2410-197 Leiria, Portugal

e-mail: hml.vasconcelos@gmail.com 
year, increased incidence of intravenous-steroid refractoriness and a higher colectomy rate.

Keywords Ulcerative colitis · NOD2 mutations · Genotypephenotype correlations $\cdot$ Disease course $\cdot$ Prognosis

\section{Introduction}

The inflammatory bowel diseases (IBDs), ulcerative colitis (UC) and Crohn's disease (CD), are chronic relapsing and remitting inflammatory conditions affecting the gastrointestinal tract. They are likely the result of a dysregulated immune response to the gut microflora in genetically predisposed individuals [1].

Over the past two decades, investigators have used whole genome linkage and genome-wide association studies, to identify over 163 genetic loci containing susceptibility genes for IBD [2]. These loci, although nearly all low-risk, have provided important lessons regarding IBD etiopathogenesis, including that $\mathrm{UC}$ and $\mathrm{CD}$ are related polygenic IBDs, with distinct and overlapping susceptibility loci $[2,3]$.

Although UC and CD share associations with many singlenucleotide polymorphisms (SNPs) in Th17/IL22-23 axis, adaptive immunity and epithelial barrier function, there are divergences between the two diseases in the NOD2 and autophagy pathway SNPs which are both associated with $\mathrm{CD}$ but not UC $[2,4,5]$.

NOD2, located on chromosome 16, was one of the earliest genes in which mutations have been shown to be associated with IBD $[6,7]$. This gene encodes a protein that functions as an intracellular sensor of muramyl-dipeptide, a component of bacterial cell walls [8]. Therefore, NOD2 mutations compromise host response to enteric bacteria [8]. Three major NOD2 SNPs, two missense [R702W, G908R] and one frameshift $(1,007 \mathrm{fs})$, were shown by independent groups to be associated with susceptibility to $\mathrm{CD}[6,7,9-11]$. By contrast, even though most available data showed no link between NOD2 mutations and susceptibility to UC, a few recent studies have reached different conclusions, and so this matter remains somewhat controversial [4, 5, 10, 12-15].

Great efforts have been made to predict disease behavior and response to treatment in IBD [16-19]. Such understanding could personalize therapy, namely early introduction of more aggressive therapies to patients at high risk or avoiding starting predictably ineffective treatments. Indeed, the ultimate goal in the genomic study of IBD is to identify biologically relevant genotype-phenotype associations and to apply them to clinical practice $[17,20]$.

Patients with UC demonstrate a certain degree of heterogeneity as the age of onset, disease extent, natural history, response to medical therapies, and need for surgery vary between individuals $[17,21,22]$. Among the UC susceptibility genes, HLA DRB $1 * 0103$ and the multidrug resistance gene 1 (MDR1/ABCB1) also contribute to clinical phenotype and natural history, being associated with extensive and severe disease [17, 23-37]. In CD, NOD2 gene mutations have repeatedly been shown to be associated with ileal disease, early age of onset, stricturing, and/or penetrating phenotype and increased need for surgery [5, 9, 10, 38-49].

Surprisingly, there are no studies focusing on potential genotype-phenotype associations between NOD2 mutations and UC, perhaps because it is not commonly considered a susceptibility gene for UC $[5,10,50]$. All genotype-phenotype UC association studies focus on genes that had previously been identified as susceptibility genes for the disease [5, 17]. Nevertheless, this may produce a bias, since one gene not related with increased susceptibility to a disease may be associated with a particular phenotype of this disease. Indeed, this lesson can clearly be taken from the study of Seghal et al. [20]. In this work, even though NOD2 mutations were not associated with the overall risk of pouchitis, a relation between the mutation carrier status and severe pouchitis was found [20]. Thus, the authors concluded that preoperative assessment of NOD2 in ileal pouch-anal anastomosis candidates may predict severe pouchitis and might assist in preoperative surgical decision making [20].

In light of these data, we aimed to investigate if $N O D 2$ mutations increase susceptibility to UC in Portugal and whether there are genotype-phenotype correlations in these patients.

\section{Methods}

Patients and controls

In this case-control study, 200 Portuguese patients with UC (male/female, 86/114; mean age at diagnosis of UC 34.8 14.4 years old) and 202 healthy (blood donors) sex-matched controls, were genotyped for the three main NOD2 mutations (R702W, G908R, and 3020insC). UC patients were consecutively recruited from a gastroenterology department in the inpatient and outpatient setting. The inclusion criteria for all study participants included Caucasian ethnicity and residency in the central region of Portugal and, for UC patients, a confirmed disease diagnosis based on established clinical, endoscopic, radiological, and histological criteria [51-53]. Patients with $\mathrm{CD}$ or colonic inflammatory bowel disease unclassified (IBDU) were excluded from the study.

Genomic DNA was isolated from whole blood in all the study participants.

Detailed phenotypic characteristics, including demographic data and clinical parameters, were obtained with a standardized questionnaire filled out by reviewing the medical charts and a patient interview at the time of enrolment. Phenotypic characteristics were classified 
according to the recently published second European evidence-based consensus on the diagnosis and management of UC [54-56]. All phenotypic data were collected blind to the results of the genotypic data.

Correlations between NOD2 mutations and UC phenotypic characteristics were sought. The associations with statistical significance in the univariate analysis were then tested in multivariate analysis using age at diagnosis and extent of disease as covariates since these are the factors most often and consistently described as having prognostic value in UC [57].

This study was approved by the local Ethics Committee and informed consent was obtained from all participants prior to enrolment into the study, in accordance with the Declaration of Helsinki.

\section{Sample DNA extraction and genotyping}

Genomic DNA was isolated from whole blood in accordance with the QIAamp Mini Kit (QIAGEN GmbH, Germany).

All participants were genotyped for the three major NOD2 mutations: 3020insC (SNP13), R702W (SNP8) and G908R (SNP12). Genotyping was performed by real-time polymerase chain reaction (PCR): 3020insC variant using SimpleProbe and variants $\mathrm{R} 702 \mathrm{~W}$ and G908R using HybProbe (FRET). In order to detect the 3020insC variant, PCR was carried out using the forward primer 5'-gACAggTgggCTTCAgTAgA-3', the reverse primer $5^{\prime}$-TgAggTTCggAgAgCTAAAACAg-3' and the simple probe 5'-CTgCAggCCCCTTgAAAg-FLQ. The R702W variant was amplified and detected using the forward primer 5'-AgCCgCACAACCTTAgATCAC-3', the reverse primer 5'-gCgggCACAggCATAgC-3', the anchor probe 5'-LC Red640-gTCTggCACT $\mathrm{CAgCCAgCAggCCCC}-\mathrm{PH}$ and the donor probe 5'gCgCCAgAgCAgggCCTTCTCA-FL. For assay of the G908R mutation, 5'-gCACATATCAggTACTCACT gACACT-3' was used as the forward primer, 5'-TTAC CTgAgCCACCTCAAgC-3' as the reverse primer, 5'-LC Red705-CTgAAAAggCCAAAAgAgTCAACAgAC-PH as the anchor probe and the 5'-CCACTCTgTTgCCCC AgAA-FL as the donor probe.

The reaction mixture consisted of $18 \mu \mathrm{l}$ of the PCR master mix plus $2 \mu$ of the DNA of each patient. The PCR master mix for the $\mathrm{R} 702 \mathrm{~W}$ variant included $5.0 \mathrm{mM} \mathrm{MgCl} 2,1 \times$ LightCycler DNA master hybridization probes (Roche, Mannheim, Germany), $0.5 \mu \mathrm{M}$ each primer and $0.1 \mu \mathrm{M}$ each fluorescein and LC-Red-640-labeled probe. Cycling parameters consisted of 1 cycle of $95{ }^{\circ} \mathrm{C}$ for $2 \mathrm{~min}$., followed by amplification for 45 cycles of $95^{\circ} \mathrm{C}$ for $0 \mathrm{~s}, 55^{\circ} \mathrm{C}$ for $10 \mathrm{~s}$, and $72{ }^{\circ} \mathrm{C}$ for $5 \mathrm{~s}$. A melting curve was created by measuring the fluorescent signal generated with the following profile: $95^{\circ} \mathrm{C}$ for $5 \mathrm{~s}, 50^{\circ} \mathrm{C}$ for $10 \mathrm{~s}$, and $90^{\circ} \mathrm{C}$ for $0 \mathrm{~s}$ with a slope $0.4{ }^{\circ} \mathrm{C} / \mathrm{s}$ transition. The PCR master mix for the G908R mutation included $2.5 \mathrm{mM} \mathrm{MgCl} 2,1 \times$ LightCycler DNA master hybridization probes (Roche, Mannheim, Germany), $0.5 \mu \mathrm{M}$ each primer and $0.2 \mu \mathrm{M}$ each fluorescein and LC-Red-705labeled probe. Cycling parameters consisted of 1 cycle of $95^{\circ} \mathrm{C}$ for $2 \mathrm{~min}$., followed by amplification for 40 cycles of $95^{\circ} \mathrm{C}$ for $10 \mathrm{~s}, 57^{\circ} \mathrm{C}$ for $8 \mathrm{~s}$, and $72^{\circ} \mathrm{C}$ for $17 \mathrm{~s}$. A melting curve was originated by measuring the fluorescent signal generated with the following profile: $95{ }^{\circ} \mathrm{C}$ for $20 \mathrm{~s}, 40{ }^{\circ} \mathrm{C}$ for $20 \mathrm{~s}$, and $85^{\circ} \mathrm{C}$ for $0 \mathrm{~s}$ with a slope $0.2{ }^{\circ} \mathrm{C} / \mathrm{s}$ transition. Finally, the PCR master mix for the 3020 ins $C$ variant included $2.5 \mathrm{mM} \mathrm{MgCl}_{2}, 1 \times$ LightCycler DNA master hybridization probes (Roche, Mannheim, Germany), $0.2 \mu \mathrm{M}$ forward primer, $0.5 \mu \mathrm{M}$ reverse primer and $0.2 \mu \mathrm{M}$ simple probe. Cycling parameters consisted of $1 \mathrm{cycle}$ of $95^{\circ} \mathrm{C}$ for $2 \mathrm{~min}$, followed by amplification for 40 cycles of $95^{\circ} \mathrm{C}$ for $10 \mathrm{~s}, 55^{\circ} \mathrm{C}$ for $10 \mathrm{~s}$, and $72^{\circ} \mathrm{C}$ for $20 \mathrm{~s}$. A melting curve was created by measuring the fluorescent signal generated with the following profile: $95^{\circ} \mathrm{C}$ for $20 \mathrm{~s}, 40^{\circ} \mathrm{C}$ for $20 \mathrm{~s}$, and $85^{\circ} \mathrm{C}$ for $0 \mathrm{~s}$ with a slope $0.2{ }^{\circ} \mathrm{C} / \mathrm{s}$ transition. Sterile water was used as a negative control. The change of fluorescence was converted to a melting peak $(\mathrm{Tm})$ by plotting the negative derivative of the fluorescent signal corresponding to the temperature $(-\mathrm{d} F / \mathrm{d} T)$ with the LightCycler software.

The sequence variations of the PCR products were confirmed by DNA sequencing.

\section{Statistical analysis}

Continuous variables were summarized using means and standard deviation and categorical variables were expressed as frequency and percentage. Standard tests were used to compare means and proportions: Student's $t$ test or Wilcoxon rank-sum test for continuous variables and MannWhitney $U$ Test, Chi-Square or Fisher's Exact Test for categorical variables, when appropriate.

Multivariate analysis was performed by logistic regression for each outcome that showed a significant correlation with NOD2 mutations in the univariate analysis using age at diagnosis and maximum extent of disease as additional covariates.

Colectomy-free survival was calculated with the KaplanMeier method and the log-rank test was employed to make comparisons between groups. Data were censored at the time of colectomy or at the patient's last recorded visit.

Only $p$ values $<0.05$ were considered significant and all $p$ values presented are two-tailed.

Each genetic variant studied was in Hardy-Weinberg equilibrium.

The data was analyzed using the IBM SPSS Statistics (IBM Co., Armonk, NY, USA) computer software for Windows (version 20.0). 


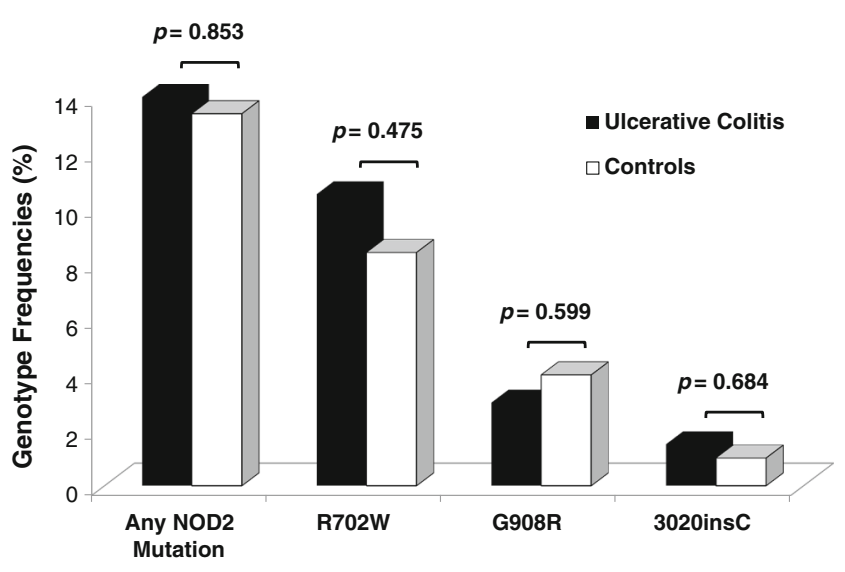

Fig. 1 Genotype frequencies of the NOD2 variants in UC patients and sex-matched controls

\section{Results}

NOD2 mutation frequency

NOD2 mutations were found in 28 patients with UC (including one R702W homozygote, one compound heterozygote $\mathrm{R} 702 \mathrm{~W} / \mathrm{G} 908 \mathrm{R}$ and another compound heterozygote G908R/3020insC) corresponding to a prevalence of $14.0 \%$. The most frequent polymorphism was R702W, present in 21 patients $(10.5 \%)$. The combined frequency of the three tested SNP's was similar between the study population and the sexmatched controls, as was the frequency of each individual genotype (Fig. 1). The NOD2 allele frequencies were in Hardy-Weinberg equilibrium in all patients and in control subjects.

Study population

\section{Demographic characteristics}

The demographic characteristics of the study population are summarized in Table 1. As shown, there are no significant differences between carriers and non-carriers of NOD2 mutations concerning age at diagnosis, gender, family history or smoking habits. Overall mean follow-up, considered as the time passed between diagnosis and last visit or colectomy, was $180.26 \pm 105.60$ months.

\section{Extent of disease}

Regarding the maximum extent of disease, $17(8.6 \%)$ patients had proctitis, 84 (42.6\%) distal colitis and 96 (48.7\%) extensive colitis. There were no significant differences in the extent of the disease (proctitis/distal colitis/extensive colitis) between patients with and those without NOD2 mutations (respectively, $11.1 \% / 37.0 \% / 51.9 \%$ vs. $8.2 \% / 43.5 \%$ / $48.2 \% ; p=0.865)$.

\section{First year of disease}

When evaluating the disease course during the first year following diagnosis, we observed that a greater proportion of patients with a NOD2 mutation required at least one course of steroids compared with non-carriers: $54.2 \%$ (13 patients) as compared with $29.6 \%$ (42 patients) $(p=0.018)$ (Table 2).

Among steroid-treated patients, even though the percentage of patients admitted for intravenous steroids was superior in the group of the mutation carriers [ 9 patients $(75.0 \%)$ vs. 20 patients (47.6\%)], it did not reach statistical significance ( $p=$ $0.113)$. Nevertheless, the carriers of the R702W variant were more likely to need the intravenous route than non-carriers of this specific mutation [9 patients $(90.0 \%)$ vs. 20 patients (45.5\%), $p=0.014$ ] (Table 2).

\section{Severe colitis}

A total of 52 patients ( $26.0 \%$ of the study population) had at least one episode of severe colitis, defined as a flare with severe activity according Truelove and Witts criteria and requiring admission and treatment with intravenous steroids $[54,58]$. There was no difference in the incidence of this event between genotype groups (Table 3 ). Significantly more patients with NOD2 carrier status were intravenous-steroid

Table 1 Demographic characteristics of the study population

\begin{tabular}{|c|c|c|c|c|c|}
\hline Variables & & All Patients & Carriers & Non-carriers & $p$ \\
\hline \multirow[t]{2}{*}{ Age at diagnosis } & $\mathrm{A} 1 / \mathrm{A} 2 / \mathrm{A} 3^{\mathrm{a}}$ & $3.0 \% / 65.5 \% / 31.5 \%$ & $7.1 \% / 57.1 \% / 35.7 \%$ & $2.3 \% / 66.9 \% / 30.8 \%$ & 0.882 \\
\hline & mean $\pm \mathrm{SD}^{\mathrm{b}}$ & $34.83 \pm 14.41$ & $35.43 \pm 14.26$ & $34.73 \pm 14.48$ & 0.811 \\
\hline Male $n(\%)$ & & $86(43.0 \%)$ & $12(42.9 \%)$ & $74(43.0 \%)$ & 0.987 \\
\hline Positive family history for IBD $n(\%)$ & & $25(12.5 \%)$ & $5(17.9 \%)$ & $20(11.6 \%)$ & 0.359 \\
\hline Positive smoking history $n(\%)$ & & $40(20.0 \%)$ & $5(17.9 \%)$ & $35(20.3 \%)$ & 0.760 \\
\hline
\end{tabular}

$S D$ Standard deviation; IBD inflammatory bowel disease

${ }^{a} A 1<16, A 2$ 16-40, $A 3>40$ years; according Montreal classification [54, 58]

${ }^{\mathrm{b}}$ Values in years 
Table 2 First year of disease

\begin{tabular}{|c|c|c|c|c|c|c|}
\hline \multirow[t]{2}{*}{ Variables } & \multicolumn{3}{|c|}{ All NOD2 mutations } & \multicolumn{3}{|c|}{ R702W polymorphism } \\
\hline & Carrier (\%) & Non-carrier (\%) & $p$ & Carrier (\%) & Non-carrier (\%) & $p$ \\
\hline$\geq 1$ flare requiring steroids $\mathrm{s}^{\mathrm{a}}$ & $54.2 \%$ & $29.6 \%$ & 0.018 & $55.6 \%$ & $30.4 \%$ & 0.032 \\
\hline$\geq 1$ admission for IV steroids ${ }^{\mathrm{b}}$ & $75.0 \%$ & $47.6 \%$ & 0.113 & $90.0 \%$ & $45.5 \%$ & 0.014 \\
\hline
\end{tabular}

$I V$ intravenous

${ }^{\text {a }}$ Data available in 166 patients

${ }^{\mathrm{b}}$ Data available in 54 patients

refractory and required salvage therapy with cyclosporine, infliximab, or colectomy as compared to NOD2 wild-type patients $(90.0 \%$ vs. $38.1 \%, p=0.004)$. Nevertheless, there was no difference between carriers and non-carriers of NOD2 polymorphisms regarding response to medical salvage therapy and therefore in the need for salvage colectomy (Table 3).

\section{Long-term disease course — treatment requirements}

The rate of steroid-dependence was similar between groups (33.3 \% vs. $27.5 \%, p=0.531)$. Even though there was no statistical difference between carriers and non-carriers regarding the rate of steroid-resistance when the three polymorphisms were studied together, we did find that patients with the polymorphism R702 W (6 patients, $28.6 \%$ ) were more often resistant to steroids than non-carriers (18 patients, $10.3 \%)(p=0.027)$. There were no significant differences between genotypes regarding the proportion of patients treated with thiopurines or infliximab.

The colectomy rate was significantly higher in carriers of NOD2 mutations than in non-carriers: $17.9 \%$ (5 patients) as compared with $4.1 \%$ (7 patients) $(p=0.015)$ (Table 4 and Fig. 2). The same behavior was observed when R702W polymorphism was considered individually (Table 4 and Fig. 2).

No patient deaths were recorded during follow-up.

\section{Multivariate analysis}

The above-described results that reached statistical significance were then tested in multivariate analysis considering age at diagnosis and extent of disease as covariates. All these correlations remained statistically significant, indicating that the NOD2-phenotype associations detected are independent from the age at diagnosis and the extent of disease (data not shown).

\section{Discussion}

IBD, including UC, has a great amount of heterogeneity, starting in the type and age of presentation, through natural history of disease and ending in the therapeutic requirements and response [17, 21, 22]. An old and still unachieved goal is to discover a way of predicting the disease evolution and thereby define a more appropriate and individually tailored monitoring and therapeutic approach [16-19]. The personalized choice of the treatment regimen may help to maximize efficacy, minimize delays to effective treatment, and improve safety and tolerability.

Therefore, an ultimate objective in the genomic study of IBD is to identify biologically relevant genotype-phenotype associations and to apply them to clinical practice $[16,17,20]$. In the past two decades, genetic variants identified as being

Table 3 Severe colitis - incidence and therapy

\begin{tabular}{|c|c|c|c|c|c|c|}
\hline \multirow[t]{2}{*}{ Variables } & \multicolumn{3}{|c|}{ All NOD2 mutations } & \multicolumn{3}{|c|}{ R702W polymorphism } \\
\hline & Carriers $n(\%)$ & Non-carriers $n(\%)$ & $p$ & Carriers $n(\%)$ & Non-carriers $n(\%)$ & $p$ \\
\hline Severe colitis ${ }^{\mathrm{a}}$ & $10(35.7 \%)$ & $42(24.4 \%)$ & 0.206 & $8(38.1 \%)$ & $44(24.6 \%)$ & 0.182 \\
\hline IV steroid refractory ${ }^{\mathrm{b}}$ & $9(90.0 \%)$ & $16(38.1 \%)$ & 0.004 & $7(87.5 \%)$ & $18(40.9 \%)$ & 0.022 \\
\hline CYA/IFX refractory ${ }^{\mathrm{c}}$ & $2(28.6 \%)$ & $2(13.3 \%)$ & 0.565 & $2(33.3 \%)$ & $2(12.5 \%)$ & 0.292 \\
\hline
\end{tabular}

$I V$ intravenous, CYA cyclosporine, IFX infliximab

${ }^{a}$ Flare with severe activity according Truelove and Witts criteria and requiring admission and treatment with intravenous steroids [54, 59]

${ }^{\mathrm{b}}$ No response to intravenous steroids and required salvage therapy with cyclosporine, infliximab, or colectomy

${ }^{\mathrm{c}}$ No response to cyclosporine and/or infliximab and required salvage colectomy 
Table 4 Long term disease course - treatment requirements

\begin{tabular}{|c|c|c|c|c|c|c|}
\hline \multirow[t]{2}{*}{ Variables } & \multicolumn{3}{|c|}{ All NOD2 mutations } & \multicolumn{3}{|c|}{ R702W polymorphism } \\
\hline & Carrier $n(\%)$ & Non-carrier $n(\%)$ & $p$ & Carrier $n(\%)$ & Non-carrier $n(\%)$ & $p$ \\
\hline Steroid-dependent $\mathrm{t}^{\mathrm{a}}$ & $9(33.3 \%)$ & $47(27.5 \%)$ & 0.531 & $7(33.3 \%)$ & $49(27.7 \%)$ & 0.587 \\
\hline Steroid refractory ${ }^{\mathrm{b}}$ & $7(25.0 \%)$ & $17(10.1 \%)$ & 0.054 & $6(28.6 \%)$ & $18(10.3 \%)$ & 0.027 \\
\hline $\mathrm{AZA} / 6-\mathrm{MP}^{\mathrm{c}}$ & $11(39.3 \%)$ & $66(38.4 \%)$ & 0.927 & $8(38.1 \%)$ & $69(38.5 \%)$ & 0.968 \\
\hline Infliximab $^{\mathrm{d}}$ & $6(21.4 \%)$ & $20(11.6 \%)$ & 0.220 & $5(23.8 \%)$ & $21(11.7 \%)$ & 0.161 \\
\hline Colectomy $^{\mathrm{e}}$ & $5(17.9 \%)$ & $7(4.1 \%)$ & 0.015 & $4(19.0 \%)$ & $8(4.5 \%)$ & 0.026 \\
\hline
\end{tabular}

$A Z A$ azathioprine; 6-MP 6-Mercaptopurine

${ }^{a}$ Data available in 198 patients

${ }^{\mathrm{b}}$ Data available in 196 patients

${ }^{\mathrm{c}}$ Data available in 200 patients

${ }^{\mathrm{d}}$ Data available in 200 patients

${ }^{\mathrm{e}}$ Data available in 200 patients

associated with increased susceptibility to IBD were then subject to research in order to investigate whether they are also correlated with the disease phenotype. NOD2, the first gene linked with increased susceptibility to $\mathrm{CD}$, has later been shown to be associated with ileal disease, early age of onset, stricturing, and/or penetrating phenotype and increased need
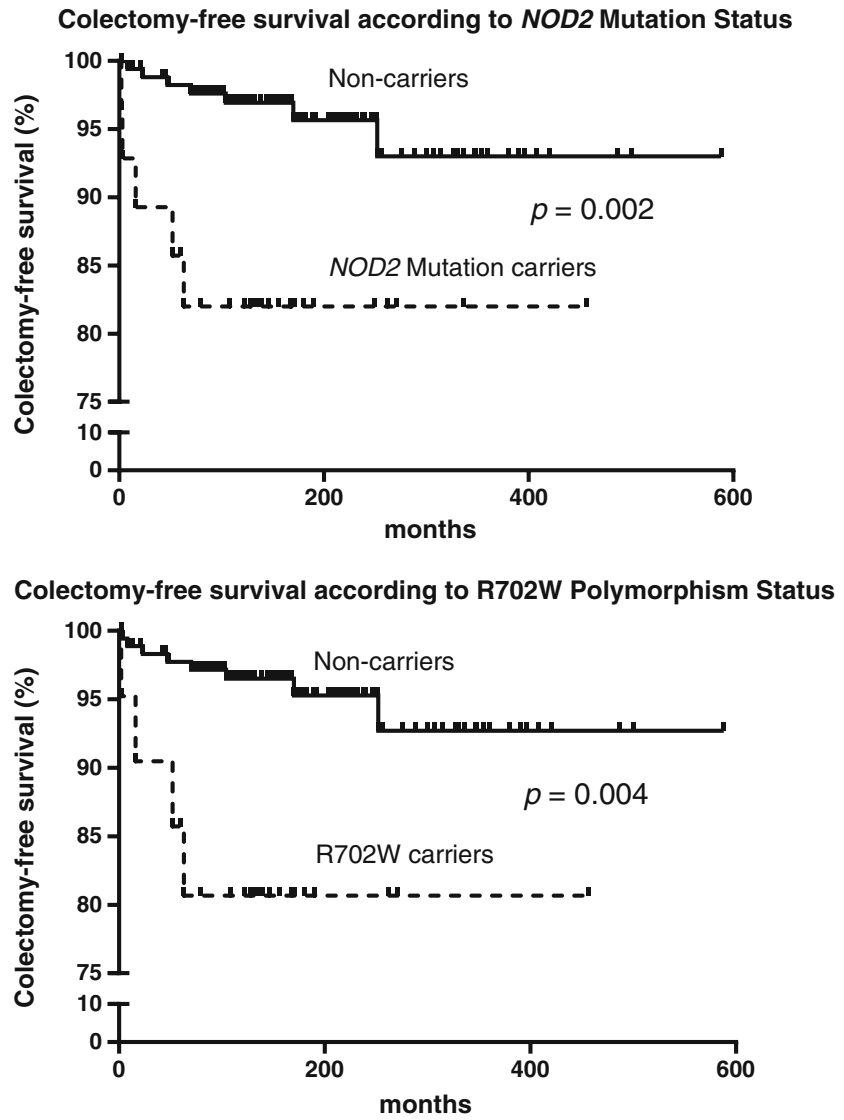

Fig. 2 Cumulative colectomy-free survival in patients with and without NOD2 mutation and R702W polymorphism for surgery $[5,9,10,38-49]$. Among the UC susceptibility genes, HLA DRB $1 * 0103$ and the multidrug resistance gene 1 (MDR1/ABCB1) were also identified as being associated with extensive and severe disease [17, 23-37].

In UC, all genotype-phenotype association studies focus on genes which have previously demonstrated association with increased susceptibility to the disease $[5,17]$. Thus, as NOD2 has not been generally linked with UC susceptibility, there are no published studies of potential associations between NOD2 genotype and UC phenotype [5]. However, this reasoning may produce a bias because a gene can be associated with a particular phenotype despite not being related with increase susceptibility to the disease. For example, Seghal et al. demonstrated that NOD2 variants are associated with severe pouchitis, although these mutations do not increase the overall risk of pouchitis [20].

Taking this data into account, this paper aimed to clarify if NOD2 mutations increased susceptibility to UC in Portugal and whether there are genotype-phenotype correlations in these patients. To our knowledge, this is the first study that sought potential associations between NOD2 mutations and phenotype, natural history or therapeutic responsiveness in patients with UC.

In line with the evidence from the majority of previous studies, we found that NOD2 mutations are not linked with increased susceptibility to UC in the Portuguese population [5, $10,50]$.

In the study population, we found that there were no associations between NOD2 mutations and demographic characteristics (age at onset, gender, and family history of IBD) or smoking habits. Similarly, the disease extent showed no correlation with NOD2 mutation status.

Regarding the disease course during the first year following diagnosis, we found that patients with a mutation of the studied gene were more likely to receive steroids for a disease 
flare (54.2 vs. $29.6 \%, p=0.018)$. Among patients who required steroids in this setting, the need for intravenous administration was significantly more frequent in those with the R702W polymorphism ( $90.0 \%$ vs. $45.5 \%, p=0.014)$.

According to our results, there was no association of any genotype with the incidence of severe colitis, defined as a flare with severe activity according Truelove and Witts criteria and requiring admission and treatment with intravenous steroids $[54,59]$. Nevertheless, NOD2 mutations were significantly associated with intravenous-steroid refractoriness and, hence, with the need for salvage therapy with cyclosporine, infliximab, or colectomy ( $p=0.004)$. By contrast, NOD2 carrier status was not associated with the response to medical salvage therapy and therefore with the need for salvage colectomy, but the small number of patients with these events advises a careful interpretation.

In addition to severe colitis episodes, the course of UC can be indirectly evaluated through the therapeutic needs and responses, including steroid-dependence, steroid-resistance, need of immunosuppressive/immunomodulatory agents and colectomy rates. In our study cohort, even though the combined three key NOD2 mutations were not associated with steroid-dependence or steroid-resistance, we found that carriers of the $\mathrm{R} 702 \mathrm{~W}$ polymorphism were more often resistant to steroids $(p=0.027)$. The need for immunosuppressants/ immunomodulators showed no significant associations with NOD2 mutations, even when R702W polymorphism was considered separately. However, both, R702W polymorphism alone and 3020insC/R702W/G908R variants together, were associated with increased need of colectomy (respectively, $p=$ 0.026 and $p=0.015$ ).

The age at diagnosis and the extent of disease are frequently and consistently identified as prognostic factors in UC [57]. In this context, the significant associations found between NOD2 gene and UC phenotype characteristics, were included in a multivariate analysis using age at diagnosis and extent of disease as covariates. This evaluation has shown that the NOD2 prognostic value detected in our work is independent of these two important variables.

Our data suggests that although NOD2 genotype does not correlate with susceptibility to UC, the mutations of this gene appear to be associated with a more aggressive course of the disease. Similar findings were reported in $\mathrm{CD}$, where NOD2 carrier status has been associated not only with a more aggressive disease phenotype but also to an increased likelihood of steroid refractoriness and a higher need for surgery $[5,9,10$, 38-49].

Surprisingly, apart from our work, there is no other study regarding potential NOD2 genotype-phenotype correlations in UC patients. Thus, further data from different and larger populations is needed to determine whether NOD2 mutations lead to a predisposition to a more aggressive UC disease course and, if so, to identify the additional determinants necessary for this increased susceptibility, namely their possible interactions with other genes, environmental factors, clinical features, and demographic data. A thorough investigation of these issues may improve knowledge of the disease pathophysiology, can shed light on the determinants of clinical UC heterogeneity and could lead to the development of new therapeutic paradigms.

This study has some limitations. Firstly, the size of the study population is relatively small. Secondly, the potential effect of other genetic and/or environmental factors and/or their interaction with NOD2 mutations has not been evaluated. Thirdly, disease course, treatment requirements and response/ remission rates were evaluated retrospectively. Finally, this work was performed in a teaching and referral hospital and therefore our results may not be applicable to institutions with different patient populations.

In conclusion, our study suggests that even tough NOD2 mutations do not confer an increased risk of UC in the Portuguese population, these genetic variants are associated with a more aggressive course of the disease, including greater need of steroids in the first year, increased incidence of intravenous-steroid refractoriness and a higher rate of colectomy. This is the first study that demonstrated a link between NOD2 genotype and UC phenotype. Regional heterogeneity within the NOD2 genotype in UC patients shows the importance of the genetic assessment and evaluation of its correlation with the phenotype in different populations $[4,5,10,12-15$, 50]. In addition, other potential genetic predictors and detailed information about environmental exposure should be assessed in future studies, because the lowpenetrance genetic effects of common SNPs may largely depend on interaction with other determinant factors. Hence, additional research, using larger patient groups as well as other populations and with the assessment of additional genetic and environmental factors, is required in order to unequivocally determine the role of NOD2 variants in UC heterogeneity. This investigation will be essential to validate our data, to provide the rationale for identifying objective predictors of disease course and that could, ultimately, be an important step toward a personalized therapy in UC patients.

Acknowledgments This study was supported by research grants awarded by: Fundação para a Ciência e Tecnologia (SFRH/SINTD/ 60055/2009), Fundação Glaxo Smith Kline das Ciências da Saúde, Sociedade Portuguesa de Endoscopia Digestiva, Faculdade de Medicina da Universidade de Coimbra (Programa de Estímulo à Investigação, En 2011) and Centro de Estudos Ibéricos. These institutions had no role in any phase of this study.

We acknowledge all our colleagues who referred cases, and the patients for generously participating in the research. We thank Dr. Jorge Tomaz and Dr. Ana Esesúmaga for providing biological material (whole blood) from blood donors. We are indebted to Carlos Alberto for this expert technical assistance. 
Conflicts of interest/disclosure The authors have no potential conflicts of interest.

\section{References}

1. Podolsky DK (2002) Inflammatory bowel disease. N Engl J Med 347:417-429

2. Brant SR (2013) Promises, delivery, and challenges of inflammatory bowel disease risk gene discovery. Clin Gastroenterol Hepatol 11:2226

3. Jostins L, Ripke S, Weersma RK, Duerr RH, McGovern DP, Hui KY et al (2012) Host-microbe interactions have shaped the genetic architecture of inflammatory bowel disease. Nature 491:119-124

4. Waterman M, Xu W, Stempak JM, Milgrom R, Bernstein CN, Griffiths AM et al (2011) Distinct and overlapping genetic loci in Crohn's disease and ulcerative colitis: correlations with pathogenesis. Inflamm Bowel Dis 17:1936-1942

5. Cho JH, Brant SR (2011) Recent insights into the genetics of inflammatory bowel disease. Gastroenterology 140:1704-1712

6. Hugot JP, Chamaillard M, Zouali H, Lesage S, Cézard JP, Belaiche J et al (2001) Association of NOD2 leucine-rich repeat variants with susceptibility to Crohn's disease. Nature 411:599-603

7. Ogura Y, Bonen DK, Inohara N, Nicolae DL, Chen FF, Ramos R et al (2001) A frameshift mutation in NOD2 associated with susceptibility to Crohn's disease. Nature 411:603-606

8. Bonen DK, Ogura Y, Nicolae DL, Inohara N, Saab L, Tanabe T et al (2003) Crohn's disease-associated NOD2 variants share a signaling defect in response to lipopolysaccharide and peptidoglycan. Gastroenterology 124:140-146

9. Hampe J, Cuthbert A, Croucher PJ, Mirza MM, Mascheretti S, Fisher $\mathrm{S}$ et al (2001) Association between insertion mutation in NOD2 gene and Crohn's disease in German and British populations. Lancet 357: $1925-1928$

10. Lesage S, Zouali H, Cézard JP, Colombel JF, Belaiche J, Almer S et al (2002) CARD15/NOD2 mutational analysis and genotypephenotype correlation in 612 patients with inflammatory bowel disease. Am J Hum Genet 70:845-857

11. Heliö T, Halme L, Lappalainen M, Fodstad H, Paavola-Sakki P, Turunen U et al (2003) CARD15/NOD2 gene variants are associated with familially occurring and complicated forms of Crohn's disease. Gut 52:558-562

12. Gazouli M, Mantzaris G, Kotsinas A, Zacharatos P, Papalambros E, Archimandritis A et al (2005) Association between polymorphisms in the Toll-like receptor 4, CD14, and CARD15/NOD2 and inflammatory bowel disease in the Greek population. World J Gastroenterol 11:681-685

13. Pugazhendhi S, Santhanam S, Venkataraman J, Creveaux I, Ramakrishna BS (2013) NOD2 gene mutations associate weakly with ulcerative colitis but not with Crohn's disease in Indian patients with inflammatory bowel disease. Gene 512:309-313

14. Yun J, Xu CT, Pan BR (2009) Epidemiology and gene markers of ulcerative colitis in the Chinese. World J Gastroenterol 15:788-803

15. Juyal G, Amre D, Midha V, Sood A, Seidman E, Thelma BK (2007) Evidence of allelic heterogeneity for associations between the NOD2/CARD15 gene and ulcerative colitis among North Indians. Aliment Pharmacol Ther 26:1325-1332

16. Niess JH, Klaus J, Stephani J, Pflüger C, Degenkolb N, Spaniol U et al (2012) NOD2 polymorphism predicts response to treatment in Crohn's disease - first steps to a personalized therapy. Dig Dis Sci 57:879-886

17. Haritunians T, Taylor KD, Targan SR, Dubinsky M, Ippoliti A, Kwon $S$ et al (2010) Genetic predictors of medically refractory ulcerative colitis. Inflamm Bowel Dis 16:1830-1840
18. Beaugerie L, Seksik P, Nion-Larmurier I, Gendre JP, Cosnes J (2006) Predictors of Crohn's disease. Gastroenterology 130:650-656

19. Loly C, Belaiche J, Louis E (2008) Predictors of severe Crohn's disease. Scand J Gastroenterol 43:948-954

20. Sehgal R, Berg A, Hegarty JP, Kelly AA, Lin Z, Poritz LS et al (2010) NOD2/CARD15 mutations correlate with severe pouchitis after ileal pouch-anal anastomosis. Dis Colon Rectum 53:1487-1494

21. Adamiak T, Walkiewicz-Jedrzejczak D, Fish D, Brown C, Tung J, Khan K et al (2013) Incidence, clinical characteristics, and natural history of pediatric IBD in Wisconsin: a population-based epidemiological study. Inflamm Bowel Dis 19:1218-1223

22. Sjöberg D, Holmström T, Larsson M, Nielsen AL, Holmquist L, Ekbom A et al (2013) Incidence and natural history of ulcerative colitis in the Uppsala Region of Sweden 2005-2009 - results from the IBD Cohort of the Uppsala Region (ICURE). J Crohns Colitis 7(9):e351-e357

23. Roussomoustakaki M, Satsangi J, Welsh K, Louis E, Fanning G, Targan S et al (1997) Genetic markers may predict disease behavior in patients with ulcerative colitis. Gastroenterology 112:1845-1853

24. Bouma G, Crusius JB, García-González MA, Meijer BU, Hellemans HP, Hakvoort RJ et al (1999) Genetic markers in clinically well defined patients with ulcerative colitis (UC). Clin Exp Immunol 115:294-300

25. de la Concha EG, Fernandez-Arquero M, Lopez-Nava G, Martin E, Allcock RJ, Conejero L et al (2000) Susceptibility to severe ulcerative colitis is associated with polymorphism in the central MHC gene IKBL. Gastroenterology 119:1491-1495

26. Yamamoto-Furusho JK, Uscanga LF, Vargas-Alarcón G, RuizMorales JA, Higuera L, Cutiño T et al (2003) Clinical and genetic heterogeneity in Mexican patients with ulcerative colitis. Hum Immunol 64:119-123

27. Ahmad T, Armuzzi A, Neville M, Bunce M, Ling KL, Welsh KI et al (2003) The contribution of human leucocyte antigen complex genes to disease phenotype in ulcerative colitis. Tissue Antigens 62:527535

28. Fernández L, Núñez C, Mendoza JL, Urcelay E, Fernández-Arquero $\mathrm{M}$, Taxonera $\mathrm{C}$ et al (2005) A recombined haplotype in the major histocompatibility region contains a cluster of genes conferring high susceptibility to ulcerative colitis in the Spanish population. Inflamm Bowel Dis 11:785-791

29. Brant SR, Panhuysen CI, Nicolae D, Reddy DM, Bonen DK, Karaliukas R et al (2003) MDR1 Ala893 polymorphism is associated with inflammatory bowel disease. Am J Hum Genet 73:1282-1292

30. Ho GT, Gaya DR, Satsangi J (2005) Multidrug resistance (MDR1) gene in inflammatory bowel disease: a key player? Inflamm Bowel Dis 11:1013-1019

31. Ho GT, Soranzo N, Nimmo ER, Tenesa A, Goldstein DB, Satsangi J (2006) ABCB1/MDR1 gene determines susceptibility and phenotype in ulcerative colitis: discrimination of critical variants using a genewide haplotype tagging approach. Hum Mol Genet 15:797-805

32. Fisher SA, Tremelling M, Anderson CA, Gwilliam R, Bumpstead S, Prescott NJ et al (2008) Genetic determinants of ulcerative colitis include the ECM1 locus and five loci implicated in Crohn's disease. Nat Genet 40:710-712

33. Franke A, Balschun T, Karlsen TH, Sventoraityte J, Nikolaus S, Mayr G et al (2008) Sequence variants in IL10, ARPC2 and multiple other loci contribute to ulcerative colitis susceptibility. Nat Genet 40: 1319-1323

34. Silverberg MS, Cho JH, Rioux JD, McGovern DP, Wu J, Annese V et al (2009) Ulcerative colitis-risk loci on chromosomes 1p36 and 12 q15 found by genome-wide association study. Nat Genet 41:216220

35. Anderson CA, Massey DC, Barrett JC, Prescott NJ, Tremelling M, Fisher SA et al (2009) Investigation of Crohn's disease risk loci in ulcerative colitis further defines their molecular relationship. Gastroenterology 136:523-529 
36. Yang H, Rotter JI, Toyoda H, Landers C, Tyran D, McElree CK et al (1993) Ulcerative colitis: a genetically heterogeneous disorder defined by genetic (HLA class II) and subclinical (antineutrophil cytoplasmic antibodies) markers. J Clin Invest 92:1080-1084

37. Stokkers PC, Reitsma PH, Tytgat GN, van Deventer SJ (1999) HLADR and -DQ phenotypes in inflammatory bowel disease: a metaanalysis. Gut 45:395-401

38. Abreu MT, Taylor KD, Lin YC, Hang T, Gaiennie J, Landers CJ et al (2002) Mutations in NOD2 are associated with fibrostenosing disease in patients with Crohn's disease. Gastroenterology 123:679-688

39. Ahmad T, Armuzzi A, Bunce M, Mulcahy-Hawes K, Marshall SE, Orchard TR et al (2002) The molecular classification of the clinical manifestations of Crohn's disease. Gastroenterology 122:854-866

40. Cuthbert AP, Fisher SA, Mirza MM, King K, Hampe J, Croucher PJ et al (2002) The contribution of NOD2 gene mutations to the risk and site of disease in inflammatory bowel disease. Gastroenterology 122 : 867-874

41. Hampe J, Grebe J, Nikolaus S, Solberg C, Croucher PJ, Mascheretti S et al (2002) Association of NOD2 (CARD15) genotype with clinical course of Crohn's disease: a cohort study. Lancet 359:1661-1665

42. Vermeire S, Wild G, Kocher K, Cousineau J, Dufresne L, Bitton A et al (2002) CARD15 genetic variation in a Quebec population: prevalence, genotype-phenotype relationship, and haplotype structure. Am J Hum Genet 71:74-83

43. Oostenbrug LE, Nolte IM, Oosterom E, van der Steege G, te Meerman GJ, van Dullemen HM et al (2006) CARD15 in inflammatory bowel disease and Crohn's disease phenotypes: an association study and pooled analysis. Dig Liver Dis 38:834-845

44. Lakatos L, Mester G, Erdelyi Z, Balogh M, Szipocs I, Kamaras G et al (2004) Striking elevation in incidence and prevalence of inflammatory bowel disease in a province of western Hungary between 1977-2001. World J Gastroenterol 10:404-409

45. Newman B, Siminovitch KA (2005) Recent advances in the genetics of inflammatory bowel disease. Curr Opin Gastroenterol 21:401-407

46. Hisamatsu T, Suzuki M, Reinecker HC, Nadeau WJ, McCormick BA, Podolsky DK (2003) CARD15/NOD2 functions as an antibacterial factor in human intestinal epithelial cells. Gastroenterology 124:993-1000

47. Seiderer J, Schnitzler F, Brand S, Staudinger T, Pfennig S, Herrmann $\mathrm{K}$ et al (2006) Homozygosity for the CARD15 frameshift mutation $1007 \mathrm{fs}$ is predictive of early onset of Crohn's disease with ileal stenosis, entero-enteral fistulas, and frequent need for surgical intervention with high risk of re-stenosis. Scand J Gastroenterol 41: $1421-1432$

48. Seiderer J, Brand S, Herrmann KA, Schnitzler F, Hatz R, Crispin A et al (2006) Predictive value of the CARD15 variant $1007 \mathrm{fs}$ for the diagnosis of intestinal stenoses and the need for surgery in Crohn's disease in clinical practice: results of a prospective study. Inflamm Bowel Dis 12:1114-1121

49. Henckaerts L, Van Steen K, Verstreken I, Cleynen I, Franke A, Schreiber S et al (2009) Genetic risk profiling and prediction of disease course in Crohn's disease patients. Clin Gastroenterol Hepatol 7:972-980

50. Rigoli L, Romano C, Caruso RA, Lo Presti MA, Di Bella C, Procopio V et al (2008) Clinical significance of NOD2/CARD15 and Toll-like receptor 4 gene single nucleotide polymorphisms in inflammatory bowel disease. World J Gastroenterol 14:4454 4461

51. Lennard-Jones JE (1989) Classification of inflammatory bowel disease. Scand J Gastroenterol Suppl 170:2-6, discussion 16-9

52. Sands BE (2004) From symptom to diagnosis: clinical distinctions among various forms of intestinal inflammation. Gastroenterology $126: 1518-1532$

53. Podolsky DK (1991) Inflammatory bowel disease (2). N Engl J Med 325:1008-1016

54. Dignass A, Eliakim R, Magro F, Maaser C, Chowers Y, Geboes K et al (2012) Second European evidence-based consensus on the diagnosis and management of ulcerative colitis part 1: definitions and diagnosis. J Crohns Colitis 6:965-990

55. Dignass A, Lindsay JO, Sturm A, Windsor A, Colombel JF, Allez M et al (2012) Second European evidence-based consensus on the diagnosis and management of ulcerative colitis part 2: current management. J Crohns Colitis 6:991-1030

56. Van Assche G, Dignass A, Bokemeyer B, Danese S, Gionchetti P, Moser G et al (2013) Second European evidence-based consensus on the diagnosis and management of ulcerative colitis part 3: special situations. J Crohns Colitis 7:1-33

57. Zallot C, Peyrin-Biroulet L (2012) Clinical risk factors for complicated disease: how reliable are they? Dig Dis 30:67-72

58. Truelove SC, Witts LJ (1955) Cortisone in ulcerative colitis; final report on a therapeutic trial. Br Med J 2:1041-1048

59. Satsangi J, Silverberg MS, Vermeire S, Colombel JF (2006) The Montreal classification of inflammatory bowel disease: controversies, consensus, and implications. Gut 55:749-753 